\title{
Food Restriction Enhances the Central Rewarding Effect of Abused Drugs
}

\author{
Soledad Cabeza de Vaca and Kenneth D. Carr \\ Millhauser Laboratories, Department of Psychiatry, New York University Medical Center, New York, New York 10016
}

Chronic food restriction increases the systemic selfadministration and locomotor-stimulating effect of abused drugs. However, it is not clear whether these behavioral changes reflect enhanced rewarding potency or a CNS-based modulatory process. The purpose of this study was to determine whether food restriction specifically increases the rewarding potency of drugs, as indexed by their threshold-lowering effect on lateral hypothalamic self-stimulation, and whether any such effect can be attributed to an enhanced central response rather than changes in drug disposition. When drugs were administered systemically, food restriction potentiated the threshold-lowering effect of amphetamine $(0.125,0.25$, and 0.5 $\mathrm{mg} / \mathrm{kg}$, i.p.), phencyclidine (1.0, 2.0, and $3.0 \mathrm{mg} / \mathrm{kg}$, i.p.), and dizocilpine (MK-801) $(0.0125,0.05$, and $0.1 \mathrm{mg} / \mathrm{kg}$, i.p.) but not nicotine $(0.15,0.3,0.45 \mathrm{mg} / \mathrm{kg}$, s.c.). When amphetamine (25.0, 50.0, and $100.0 \mu \mathrm{g})$ and MK-801 (5.0, 10.0, and $20.0 \mu \mathrm{g})$ were

Drugs of abuse appear to achieve their rewarding effects by activating the neuronal circuitry that mediates incentivemotivating effects of natural reinforcers, such as food and sex (Wise, 1982; Di Chiara and North, 1992; Koob, 1992). Behaviorally, an association between "appetites" for drugs and food has been demonstrated in several ways. Self-administration and locomotor responses to amphetamine and morphine covary with the propensity to ingest sweet solutions (Sills and Vaccarino, 1994; Gosnell et al., 1995; Sills and Crawley, 1996), and food restriction increases self-administration of a wide range of abused drugs (for review, see Carroll and Meisch, 1984). Food-restricted animals are also more responsive to the locomotor-stimulating effects of amphetamine, cocaine, and morphine (Campbell and Fibiger, 1971; Deroche et al., 1993; Marinelli et al., 1996). These observations have led to the hypothesis that food restriction increases the reinforcing potency of drugs (Carroll and Meisch, 1984) by sensitizing the neural substrate for reward (Carr, 1996; Piazza and Le Moal, 1996). However, several empirical questions that bear importantly on this hypothesis remain to be addressed.

First, apparent changes in drug potency could result from changes in pharmacokinetics and bioavailability. Food restriction alters hepatic drug-metabolizing enzyme activity (Ma et al., 1989), decreases drug binding to plasma protein (Gugler et al.,

\footnotetext{
Received March 10, 1998; revised June 23, 1998; accepted June 25, 1998.

This research was supported by National Institutes of Health Grant DA03956, Research Scientist Development Award DA00292 (K.C.), and National Institute on Drug Abuse Postdoctoral Training Grant DA07254 (S.C.V.). We thank M. Kandawire for excellent technical assistance.

Correspondence should be addressed to Dr. Kenneth D. Carr, Millhauser Laboratories, New York University Medical Center, 550 First Avenue, New York, NY 10016

Copyright (ㄷ) 1998 Society for Neuroscience $\quad 0270-6474 / 98 / 187502-09 \$ 05.00 / 0$
}

administered via the intracerebroventricular route, food restriction again potentiated the threshold-lowering effects and increased the locomotor-stimulating effects of both drugs. These results indicate that food restriction increases the sensitivity of neural substrates for rewarding and stimulant effects of drugs. In light of work that attributes rewarding effects of MK-801 to blockade of NMDA receptors on medium spiny neurons in nucleus accumbens, the elements affected by food restriction may lie downstream from the mesoaccumbens dopamine neurons whose terminals are the site of amphetamine-rewarding action. Possible metabolic-endocrine triggers of this effect are discussed, as is the likelihood that mechanisms mediating the modulatory effect of food restriction differ from those mediating sensitization by intermittent drug exposure.

Key words: food restriction; sensitization; reward; locomotion; amphetamine; MK-801; self-stimulation
1974), and increases permeability of the blood-brain barrier (Sharma et al., 1991). Food-restricted rats attain substantially higher brain concentrations of phencyclidine (PCP) (Woolverton et al., 1980) and cocaine (Angel, 1969) after intraperitoneal injection. Second, to the extent that potentiated drug responses result from increased sensitivity of a neural substrate, attribution to elements that mediate reward function requires stronger and more direct evidence than currently exists. Although behavioral controls in the self-administration studies have excluded nonspecific increases in behavioral activity (Carroll and Meisch, 1984), other explanations for increased self-administration, such as amelioration of persistent hunger, cannot be excluded. Further, an augmentation of drug-induced locomotion does not imply increased rewarding potency. After the proposal that reward and locomotion are homologous (Wise and Bozarth, 1987), evidence for the dissociability of these behavioral functions and their neural substrates has accumulated (Robledo et al., 1993; Phillips et al., 1994). Recent findings indicate that although intermittent exposure to amphetamine, morphine, $\mathrm{PCP}$, and cocaine sensitize the locomotor response to these drugs, there is no accompanying sensitization of their threshold-lowering effect on brain stimulation reward (Bauco et al., 1993; Carlezon and Wise, 1993; Wise and Munn, 1993; Bauco and Wise, 1997). Thus, although locomotor sensitization is a well established consequence of intermittent drug exposure (for review, see Pierce and Kalivas, 1997), it may not extend to drug-rewarding effects.

The rewarding effect of medial forebrain bundle electrical stimulation summates with the rewarding effect of abused drugs insofar as most drugs of abuse lower the threshold for selfstimulation (for review, see Kornetsky and Esposito, 1979; Wise, 1996). In the case of PCP, amphetamine, and dizocilpine (MK- 
801), the anatomical site of summation has been localized to the nucleus accumbens (NAC) (Colle and Wise, 1988; Carlezon and Wise, 1996a). NAC is also an anatomical site in which these compounds are self-administered (Hoebel et al., 1983; Carlezon and Wise, 1996b). Consequently, the threshold-lowering effects of these drugs on lateral hypothalamic self-stimulation (LHSS) may be used as a sensitive and reliable index of drug-rewarding potency (for review, see Wise, 1996). In light of the issues itemized above, this study examined whether the potentiation of drug self-administration and locomotion by food restriction extends to the threshold-lowering effect on LHSS and whether any such effect can be attributed to a CNS-based modulatory process rather than altered pharmacokinetics and bioavailability.

\section{MATERIALS AND METHODS}

\section{Subjects and surgical procedures}

All subjects were 350-400 gm male Sprague Dawley rats housed individually in plastic cages with access to food and water ad libitum, except when food restriction conditions applied (see below). Animals were maintained on a $12 \mathrm{hr}$ light/dark cycle with lights on at 7:00 A.M., and behavioral testing was always conducted during the light phase. Several days after arrival in the central animal facility, each rat was anesthetized with ketamine $(100 \mathrm{mg} / \mathrm{kg}$, i.p.) and xylazine $(10 \mathrm{mg} / \mathrm{kg}$, i.p.) and stereotaxically implanted with a $0.25 \mathrm{~mm}$ diameter monopolar stimulating electrode (Plastics One, Roanoke, VA) in the lateral hypothalamic medial forebrain bundle $(3.0 \mathrm{~mm}$ posterior to bregma, $1.6 \mathrm{~mm}$ lateral to the sagittal suture, and $8.6 \mathrm{~mm}$ ventral to skull surface). An anterior ipsilateral stainless steel skull screw served as ground. The one exception to this methodology concerns the nicotine study in which rats were implanted with a $0.2 \mathrm{~mm}$ diameter bipolar electrode. The subset of rats that were to receive intracerebroventricular drug injections were also implanted with a 26 gauge guide cannula (Plastic One), containing an occlusion stylet aimed at the lateral ventricle contralateral to the stimulating electrode $(1.0 \mathrm{~mm}$ posterior to bregma, $1.6 \mathrm{~mm}$ lateral to the midline suture, and $3.4 \mathrm{~mm}$ ventral to skull surface). The electrode, ground, and cannula were permanently secured to the skull by flowing dental acrylic around them and three additional mounting screws.

\section{Behavioral test apparatus}

Electrical brain stimulation. Brain stimulation training and testing were conducted in four standard operant test chambers $(26 \times 26 \times 21 \mathrm{~cm})$ placed within sound-attenuating cubicles. Each chamber had a retractable lever mounted on one wall and a house light mounted on the opposite wall. Four constant current stimulators (PHM-152B/2; MedAssociates, Georgia, VT) were used to deliver trains of $0.1 \mathrm{msec}$ cathodal pulses, which were conducted to implanted electrodes by way of commutators and flexible cables. Electrical stimulation, contingencies, and data recording were controlled through an IBM personal computer and interface (Med-Associates). All stimulation parameters were monitored on a Tektronix (TAS 455) oscilloscope.

Locomotion. The tests of locomotor activity were conducted in two shuttle boxes $(45 \times 21 \times 30 \mathrm{~cm})$, each with a front and rear sensor located (lengthwise) just above the stainless steel floor grid. The sensor contained eight invisible infrared light beams that allowed determination of the animal's position within the apparatus. Each movement across the midline (i.e., crossover from one side to the other) was detected and recorded using an IBM personal computer and interface (Shuttle-Scan; Omnitech Electronics, Columbus, OH). Locomotion scores consisted of the total number of crossings within a 30 min test period.

\section{Self-stimulation training}

After 1 week of postsurgical recovery, rats were exposed to the operant chamber and trained to lever press for $0.5 \mathrm{sec}$ trains of lateral hypothalamic stimulation at a frequency of 100 pulses per second (pps). The initial stimulation intensity of $120 \mu \mathrm{A}$ was systematically manipulated to locate the lowest intensity for each rat that would maintain vigorous lever pressing with no signs of aversive or motoric side effects. This initial screening was followed on subsequent days by training in a discrete trials procedure. Each training session consisted of 2460 -sec trials. Each trial was initiated by extension of the response lever and a $2 \mathrm{sec}$ train of "priming" stimulation. Each trial was terminated by retraction of the lever and followed by a $10 \mathrm{sec}$ intertrial interval. Each lever press produced a $1 \mathrm{sec}$ train of stimulation, except for those presses emitted during the $1 \mathrm{sec}$ train that did not increase reinforcement density. The number of lever presses and reinforcements were recorded for each trial.

Discrete trials training was followed by rate-frequency training, which continued for $\sim 2$ weeks. Rate-frequency curves were generated by presenting 12 trials in which the frequency of brain stimulation decreased in $0.05 \log$ units over successive trials from an initial frequency of $100 \mathrm{pps}$ to a terminal frequency of $28 \mathrm{pps}$. Two such series were presented in each training session.

\section{Food restriction}

Once rate-frequency responding had clearly stabilized, rats were paired based on maximum reinforcement rate and shape of the rate-frequency function, and each member of a pair was randomly assigned to either an "ad libitum" or a "restricted" feeding condition. Rats assigned to the restricted feeding condition received a single $10 \mathrm{gm}$ meal (Purina rat chow) each day in the home cage. This represented $40-50 \%$ of ad libitum intake in the control group. Rate-frequency testing continued periodically over the next 15-20 d until body weights of food-restricted rats had decreased by $\sim 20 \%$. During this period, rate-frequency curves of several restricted and ad libitum fed rats shifted appreciably $(>10 \%)$ to the left and right, respectively. In those cases, current adjustments were made just before drug testing so that average rate-frequency curves of the two groups were in approximately overlapping positions (see Results). During the subsequent drug testing period (10-12 d), feeding of the restricted group was titrated to maintain body weight loss of $20-25 \%$.

\section{Drugs and dose-response testing}

During drug testing, each session began with a preinjection test consisting of three rate-frequency series. The first series was considered to be a warm-up, and data were not included in the calculation of preinjection LHSS parameters. Injection of drug or saline vehicle was followed by a postinjection interval that varied depending on the drug injected, which, in turn, was followed by a postinjection test consisting of two ratefrequency series. A complete dose-response study consisted of four sessions, spaced at least $48 \mathrm{hr}$ apart. For each dose-response study, the order in which vehicle and drug doses were administered was counterbalanced across subjects and sessions, with treatments matched across groups each day.

Systemic D-amphetamine. The effect of D-amphetamine sulfate $(\mathrm{Na}-$ tional Institute on Drug Abuse, Rockville, MD) was tested in nine food-restricted and nine ad libitum fed rats. During the food restriction period before drug testing, the mean body weight of food-restricted rats declined from 462 to $367 \mathrm{gm}$, whereas the mean body weight of control rats increased from 459 to $480 \mathrm{gm}$. Amphetamine doses of 0.0, 0.10, 0.25, and $0.50 \mathrm{mg} / \mathrm{kg}$ were administered intraperitoneally $10 \mathrm{~min}$ before the postinjection test. For this and all other systemic dose-response studies, the drug was dissolved in $0.9 \% \mathrm{NaCl}$ and administered in a volume of $1 \mathrm{ml} / \mathrm{kg}$.

Systemic PCP. Three days after the completion of amphetamine testing, the same subjects were run in a PCP dose-response study. PCP (National Institute on Drug Abuse) was administered intraperitoneally in doses of $0.0,1.0,2.0$, and $3.0 \mathrm{mg} / \mathrm{kg} 10 \mathrm{~min}$ before postinjection testing.

Systemic MK-801. Two new groups of 10 food-restricted and $10 \mathrm{ad}$ libitum fed rats were tested for the effect of MK-801 on LHSS. By the first day of drug testing, the mean body weight of the food-restricted rats had declined from a baseline value of 433 to $343 \mathrm{gm}$. In contrast, the mean body weight of control rats had increased from 437 to $468 \mathrm{gm}$. Intraperitoneal administration of MK-801 (Research Biochemicals, Natick, MA) in doses of $0.0,0.025,0.05$, and $0.10 \mathrm{mg} / \mathrm{kg}$ was followed by a $30 \mathrm{~min}$ interval in the home cage before commencement of the postinjection test.

Systemic nicotine. Two new groups of seven food-restricted and seven ad libitum fed rats were tested as to the effects of nicotine on LHSS. By the first day of drug testing, the mean body weight of food-restricted rats had decreased from the baseline value of 458 to $362 \mathrm{gm}$. The mean body weight of controls had increased from 450 to $482 \mathrm{gm}$. (-)-Nicotine tartrate (Sigma, St. Louis, MO) in doses of $0.0,0.05,0.15$, and $0.45 \mathrm{mg} / \mathrm{kg}$ (base) was administered subcutaneously $10 \mathrm{~min}$ before the postinjection test. To induce tolerance to the activity-depressant effect that nicotine produces in drug naïve rats (Stolerman et al., 1974), the drug was administered $(0.45 \mathrm{mg} / \mathrm{kg}$, s.c.) in the home cage on 3 separate days during the week preceding drug testing.

Intraventricular MK-801. Two new groups of seven food-restricted and 
Table 1. Group mean ( \pm SEM) self-stimulation parameters at the time of drug dose-response testing

\begin{tabular}{|c|c|c|c|c|}
\hline \multirow[b]{2}{*}{ Experiment } & \multicolumn{2}{|c|}{ Reward threshold (pps) } & \multicolumn{2}{|c|}{ Maximum reinforcement rate } \\
\hline & Ad libitum & Restricted & Ad libitum & Restricted \\
\hline Amphetamine (i.p.) & $65.9 \pm 3.0$ & $64.8 \pm 2.3$ & $35.9 \pm 1.4$ & $34.0 \pm 1.9$ \\
\hline PCP (i.p.) & $63.2 \pm 2.4$ & $63.2 \pm 1.8$ & $38.4 \pm 1.4$ & $39.8 \pm 0.9$ \\
\hline MK-801 (i.p.) & $70.8 \pm 3.1$ & $71.7 \pm 2.3$ & $35.8 \pm 1.2$ & $34.8 \pm 1.0$ \\
\hline Nicotine (s.c.) & $71.7 \pm 2.3$ & $63.8 \pm 3.2$ & $34.0 \pm 1.8$ & $37.3 \pm 1.5$ \\
\hline MK-801 (i.c.v.) & $74.1 \pm 2.3$ & $69.5 \pm 3.6$ & $34.8 \pm 1.5$ & $36.6 \pm 0.8$ \\
\hline Amphetamine (i.c.v.) & $68.3 \pm 4.4$ & $66.2 \pm 4.0$ & $37.3 \pm 2.0$ & $38.7 \pm 2.3$ \\
\hline
\end{tabular}

nine ad libitum fed rats were tested for the effects of intracerebroventricular MK-801 on LHSS and locomotion. By the first day of drug testing, the mean body weight of food-restricted rats had declined from 476 to $384 \mathrm{gm}$, and body weight of ad libitum fed controls had increased from 472 to $505 \mathrm{gm}$. MK-801 was administered intracerebroventricularly in doses of $0.0,5.0,10.0$, and $20.0 \mu \mathrm{g}$. Drug solutions were loaded into a $30 \mathrm{~cm}$ length of PE-50 tubing attached at one end to a $250 \mu \mathrm{l}$ Hamilton syringe filled with distilled water and at the other end to a 33 gauge injector cannula that extended $1.0 \mathrm{~mm}$ beyond the implanted guide. The syringe was mounted on a Harvard 2272 microliter syringe pump that delivered the $5.0 \mu \mathrm{l}$ injection volume over a period of $95 \mathrm{sec}$. One minute after injections, injector cannulas were removed, stylets were replaced, and animals were returned to the test chambers where postinjection tests were initiated $5 \mathrm{~min}$ after completion of the intracerebroventricular injection. The accuracy of cannula placements was verified 2 weeks before drug testing by demonstrating an immediate (i.e., $<60$ sec latency) and sustained drinking response to $100 \mathrm{ng}$ of angiotensin II.

Two days after completion of the dose-response study, a test of MK-801-induced locomotion was conducted. On the first day, rats were placed in the shuttle boxes for an initial habituation session in which the total number of crossings in 30 min was counted. In the next two sessions, spaced $48 \mathrm{hr}$ apart, rats were tested after microinjections of either saline or a $20.0 \mu \mathrm{g}$ dose of MK-801, which were presented in counterbalanced order.

Intraventricular D-amphetamine. Three days after the last MK-801 test, five of the food-restricted and eight of the control rats were used to test the effect on LHSS of $0.0,25.0,50.0$, and $100.0 \mu \mathrm{g}$ intraventricular doses of D-amphetamine following the same procedures described for MK-801 testing. Similarly, $3 \mathrm{~d}$ after the completion of LHSS testing, locomotor responses to intracerebroventricular saline and $100.0 \mu \mathrm{g}$ amphetamine were also tested.

\section{Data analysis}

The average preinjection and postinjection rate-frequency curves obtained for each rat per session were used to derive two LHSS parameters that can be used to distinguish between changes in reward potency and performance capacity (Edmonds and Gallistel, 1974; Miliaressis et al., 1986). The asymptotic (or maximum) reinforcement rate, which is reflective of performance capacity, was described by a line that paralleled the $x$-axis and was defined as the mean of all consecutive values within $10 \%$ of the highest rate for the curve. All remaining values formed the descending portion of the curve, with the lowest point being at the highest frequency to produce $<2.5$ reinforcements per minute. Regression analysis of the descending portion of the curve was used to calculate the reward threshold (log pulse frequency sustaining half of the maximum reinforcement rate), which is reflective of reward potency. After calculation of the reward threshold, antilog transformations were applied, and natural frequencies were used to calculate the percentage of change occurring in the postinjection test relative to the preinjection test.

For each parameter, treatment effects were evaluated by two-way mixed ANOVA with the drug dose (4) as a within-subjects factor and feeding (2) as a between-subjects factor (SPSS/PC software). Because the experimental hypothesis and pilot work predicted a potentiated threshold-lowering effect of drugs in food-restricted rats, unidirectional comparisons between groups at each dose level were performed using the pooled error term from the ANOVA in the denominator of a $t$ statistic.

Effects of intracerebroventricular injections on locomotion were determined by normalizing the positively skewed distribution of locomotor

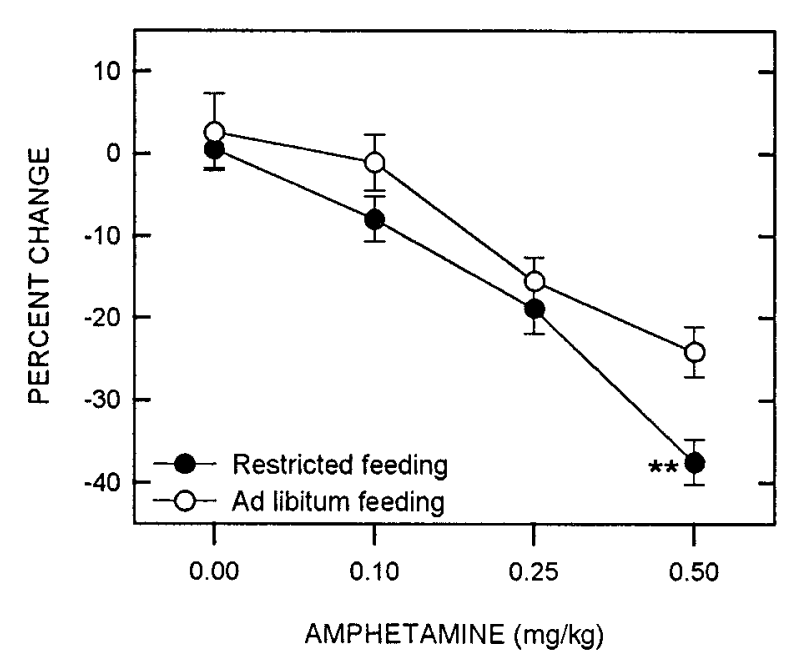

Figure 1. Mean \pm SEM percentage of change in reward threshold as a function of D-amphetamine dose for food-restricted ( filled circles) and ad libitum fed (open circles) rats. Reward thresholds were derived from LHSS rate-frequency curves obtained immediately before and $10 \mathrm{~min}$ after intraperitoneal injection of D-amphetamine. ${ }^{* *} p<0.01$.

scores using a logarithmic transform, followed by independent groups unidirectional $t$ tests.

\section{Histology}

On the completion of behavioral testing, rats were overdosed with sodium pentobarbital $(100 \mathrm{mg} / \mathrm{kg}$, i.p.), and brains were removed. After a minimum of $48 \mathrm{hr}$ in $10 \%$ buffered formalin, $30-\mu \mathrm{m}$-thick frozen coronal sections were cut on a minotome cryostat (International Equipment Co.) and stained with cresyl violet.

\section{RESULTS}

At the outset of each dose-response study, the average ratefrequency curves for food-restricted and ad libitum fed groups were approximately the same. This is reflected in the similar mean reward thresholds and maximum reinforcement rates that characterized rate-frequency curves of the two groups in each of the six drug studies (Table 1).

\section{Systemic D-amphetamine}

D-Amphetamine produced a significant decrease in the reward threshold $\left(F_{(3,48)}=45.66 ; p<0.001\right)$, with food-restricted animals displaying a greater decrease than free-feeding controls $\left(F_{(1,16)}=6.11 ; p=0.025\right)$ (Fig. 1). Comparisons between feeding conditions at each dose level indicated that food restriction significantly potentiated the threshold-lowering effect of amphetamine at the $0.50 \mathrm{mg} / \mathrm{kg}$ dose $\left(t_{(16)}=2.97 ; p<0.01\right)$. Neither D-amphetamine $\left(F_{(3,48)}=1.17\right)$ nor feeding condition $\left(F_{(1,16)}=\right.$ 

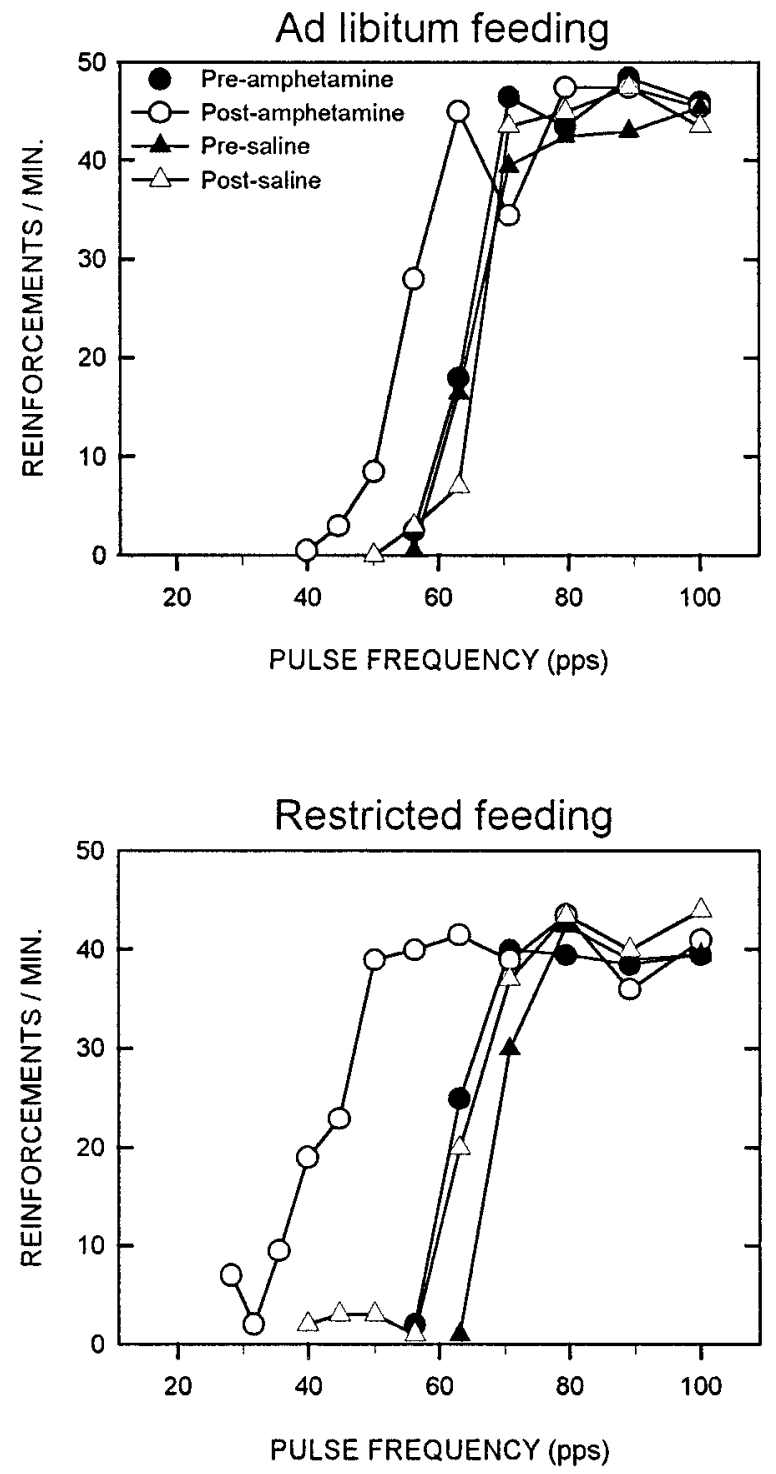

Figure 2. Representative LHSS rate-frequency curves obtained in preinjection and postinjection tests on a saline treatment day and amphetamine treatment day $(0.5 \mathrm{mg} / \mathrm{kg}$, i.p.) for one ad libitum fed (top) and one food-restricted (bottom) rat.

$0.40)$ significantly altered the maximum reinforcement rate, nor did an interaction between factors affect this measure $\left(F_{(3,48)}=\right.$ 0.04). A set of representative rate-frequency curves for ad libitum fed and food-restricted rats receiving the $0.5 \mathrm{mg} / \mathrm{kg}$ dose of amphetamine are displayed in Figure 2.

Because animals may emit lever press responses during brain stimulation trains, maximum response rate can attain higher values than maximum reinforcement rate and may therefore be a more sensitive index of performance capacity. A disadvantage of this measure is that idiosyncratic lever pressing patterns make response rates much more variable than reinforcement rates, substantially increasing the within-group variance. When ratefrequency functions were analyzed using response rate as the dependent measure, amphetamine produced an increase in maximum rate that approached statistical significance $\left(F_{(3,48)}=2.63\right.$; $p=0.06)$. However, there was no differential effect of feeding condition $\left(F_{(1,16)}=0.04\right)$ and no interaction between amphetamine and feeding condition $\left(F_{(3,48)}=0.12\right)$.

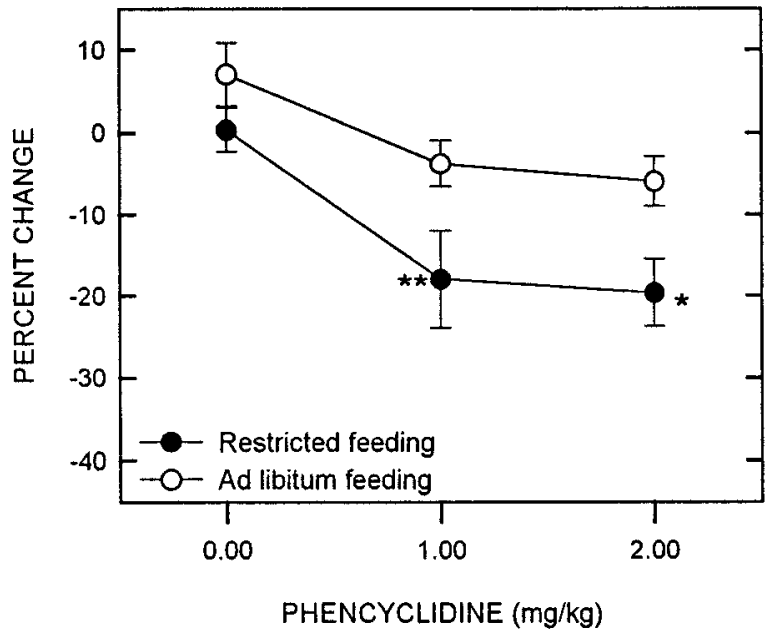

Figure 3. Mean \pm SEM percentage of change in reward threshold as a function of PCP dose for food-restricted (filled circles) and ad libitum fed (open circles) rats. Reward thresholds were derived from LHSS ratefrequency curves obtained immediately before and 10 min after intraperitoneal injection of PCP. ${ }^{*} p<0.05 ;{ }^{* *} p<0.01$.

\section{Systemic PCP}

PCP produced a significant decrease in reward threshold $\left(F_{(2,32)}\right.$ $=12.79 ; p<0.001)$, with food-restricted rats displaying a greater decrease than controls $\left(F_{(1,16)}=9.98 ; p<0.01\right)$ (Fig. 3). Comparisons between groups at each dose level revealed that food restriction potentiated the threshold-lowering effect of PCP at both the $1.0\left(t_{(16)}=258 ; p<0.01\right)$ and $2.0 \mathrm{mg} / \mathrm{kg}$ doses $\left(t_{(16)}=\right.$ $2.49 ; p<0.05)$. Neither PCP $\left(F_{(2,32)}=1.54\right)$ nor feeding condition $\left(F_{(1,16)}=0.09\right)$ significantly affected the maximum reinforcement rate, nor did an interaction between factors affect this measure $\left(F_{(2,32)}=0.87\right)$. Similarly, maximum response rate was unaffected by PCP $\left(F_{(2,32)}=1.14\right)$, feeding condition $\left(F_{(1,16)}=\right.$ $0.15)$, and their interaction $\left(F_{(2,32)}=2.36\right)$.

Data for the $3.0 \mathrm{mg} / \mathrm{kg}$ dose of PCP have been omitted from the LHSS analysis. This dose produced behavioral deficits that differed between groups and within groups. In the control group, three rats were hypoactive and ataxic, whereas in the foodrestricted group, six rats were hyperactive and ataxic. These effects emerged within 5 min of injection and tended to increase during the session to the extent that some animals were unable to finish the behavioral test.

\section{Systemic MK-801}

MK-801 produced a significant decrease in reward threshold $\left(F_{(3,54)}=14.32 ; p<0.001\right)$, with food-restricted animals displaying a greater decrease than free-feeding controls $\left(F_{(1,18)}=6.26\right.$; $p<0.025$ ) (Fig. 4). Comparisons between groups at each MK801 dose level revealed a potentiated threshold-lowering effect in food-restricted rats at the $0.1 \mathrm{mg} / \mathrm{kg}$ dose level $\left(t_{(18)}=2.58 ; p<\right.$ $0.01)$. Maximum reinforcement rate was not affected by either MK-801 $\left(F_{(1,18)}=0.03\right)$ or feeding condition $\left(F_{(3,54)}=1.77\right)$. However, there was a significant interaction between MK-801 and feeding condition $\left(F_{(3,54)}=3.52 ; p<0.025\right)$, which was accounted for by a small decrease in the maximum reinforcement rate of food-restricted rats relative to ad libitum fed rats at the $0.1 \mathrm{mg} / \mathrm{kg}$ dose level $\left(t_{(18)}=2.53 ; p<0.025\right)$. Using response rate as the measure of performance capacity, $\mathrm{MK}-801$ was shown to produce a small but significant general increase $\left(F_{(3,54)}=2.82 ; p<0.05\right)$, with no differential effect of feeding condition $\left(F_{(1,18)}=0.4\right)$. 


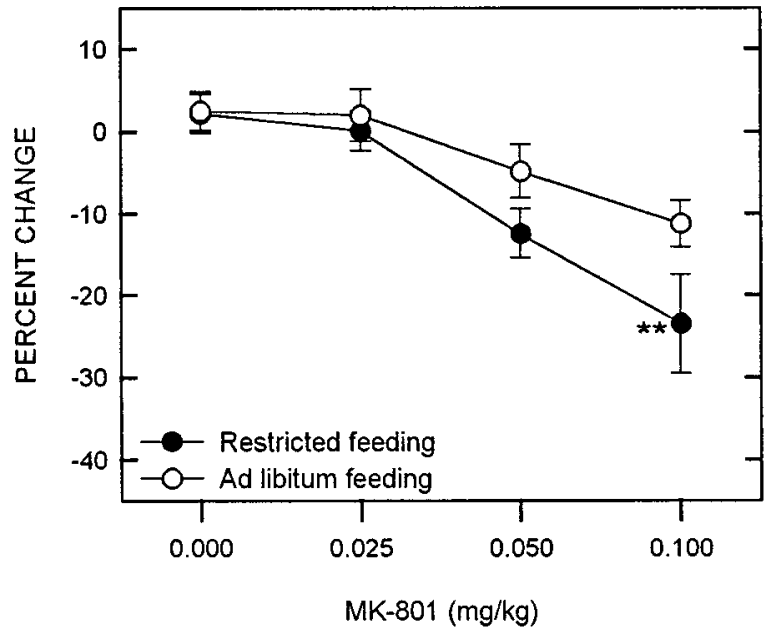

Figure 4. Mean \pm SEM percentage of change in reward threshold as a function of MK-801 dose for food-restricted ( filled circles) and ad libitum fed (open circles) rats. Reward thresholds were derived from LHSS rate-frequency curves obtained immediately before and $30 \mathrm{~min}$ after intraperitoneal injection of MK-801. ${ }^{* *} p<0.01$.

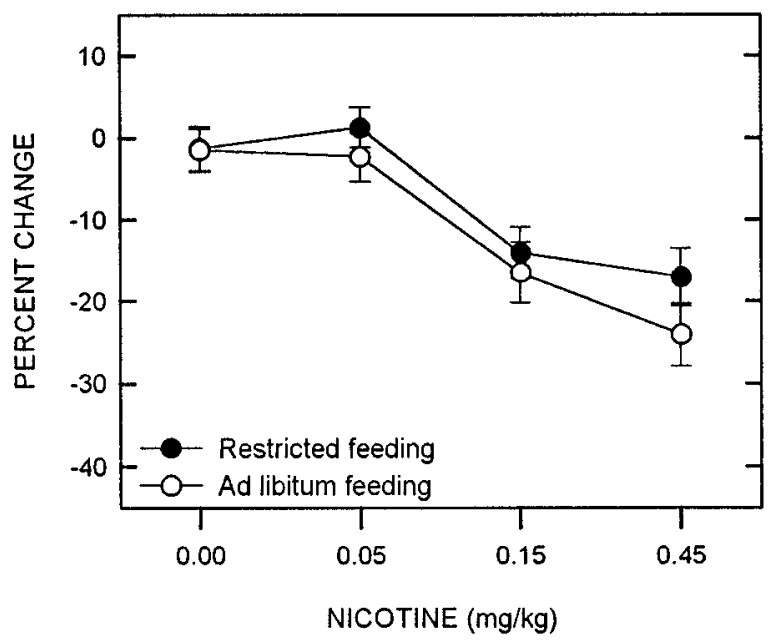

Figure 5. Mean \pm SEM percentage of change in reward threshold as a function of nicotine dose for food-restricted (filled circles) and ad libitum fed (open circles) rats. Reward thresholds were derived from LHSS rate-frequency curves obtained immediately before and $10 \mathrm{~min}$ after subcutaneous injection of nicotine.

Although the maximum rate of food-restricted rats was again slightly lower than controls at the $0.1 \mathrm{mg} / \mathrm{kg}$ dose level, the interaction effect was not significant $\left(F_{(3,54)}=1.71\right)$.

\section{Systemic nicotine}

Although nicotine produced a decrease in the reward threshold $\left(F_{(3,36)}=23.44 ; p<0.001\right)$, there was no difference between feeding conditions $\left(F_{(1,12)}=1.61\right)$ and no interaction between nicotine and feeding condition $\left(F_{(3,36)}=0.47\right)$ (Fig. 5).

\section{Intraventricular MK-801}

When injected into the lateral ventricle, MK-801 produced a significant decrease in reward threshold $\left(F_{(3,42)}=31.43 ; p<\right.$ $0.001)$. However, the potentiated effect in the food-restricted group did not attain statistical significance $\left(F_{(1,14)}=2.47 ; p=\right.$ 0.14) (Fig. 6, top). Subsequent comparisons between groups at each dose level did reveal a significantly greater threshold-
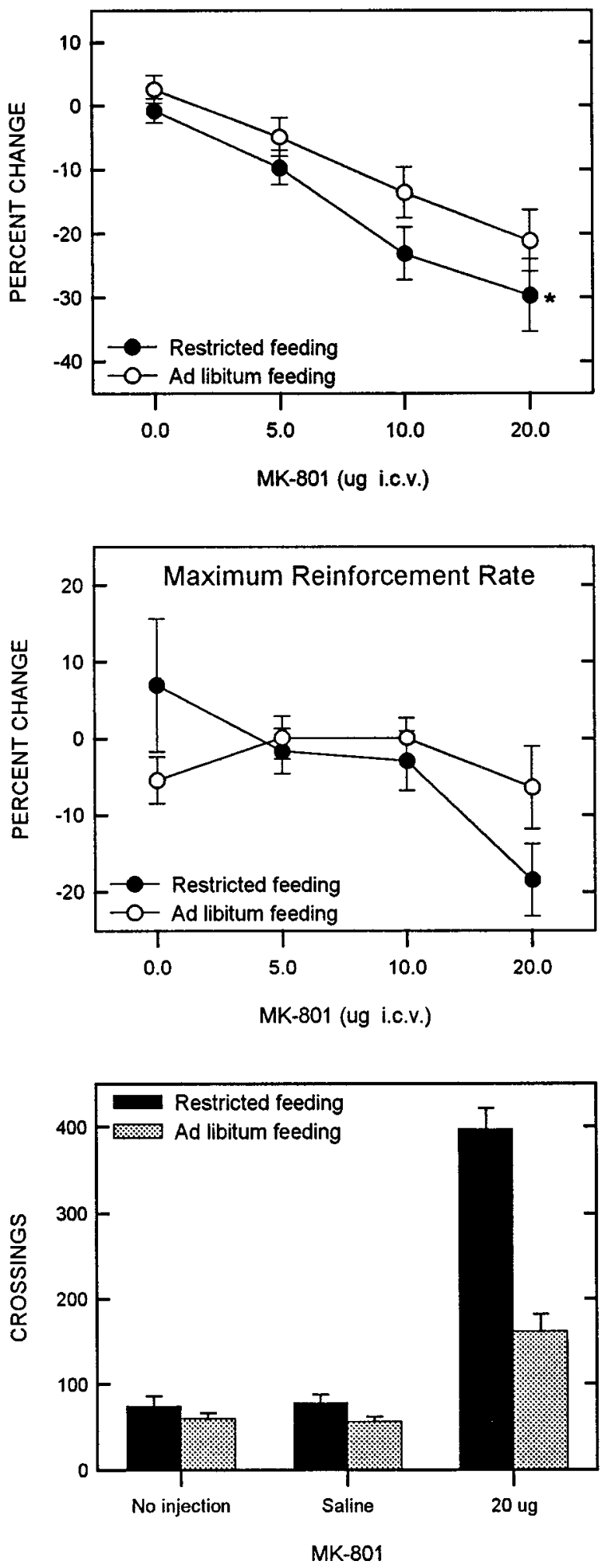

Figure 6. Mean \pm SEM percentage of change in reward threshold (top) and maximum reinforcement rate (middle) as a function of MK-801 dose for food-restricted (filled circles) and ad libitum fed (open circles) rats. LHSS parameters were derived from rate-frequency curves obtained immediately before and $5 \mathrm{~min}$ after intracerebroventricular injection of MK-801. Bottom displays the mean number of crossings in a shuttle box during three 30 min tests: (1) an initial no injection habituation test, (2) 5 min after intracerebroventricular injection of saline, and (3) 5 min after intracerebroventricular injection of $20.0 \mu \mathrm{g}$ of MK-801. 
lowering effect of the $20.0 \mu \mathrm{g}$ dose in food-restricted rats $\left(t_{(14)}=\right.$ $1.86 ; p<0.05)$.

Although feeding conditions did not affect maximum reinforcement or response rates $\left(F_{(1,14)}=0.43 ; F_{(1,15)}=1.47\right.$, respectively), MK-801 did affect these parameters $\left(F_{(3,42)}=3.38 ; p<\right.$ $0.05 ; F_{(3,42)}=5.79 ; p<0.01$, respectively). Direct observation of rats indicated a variety of behavioral changes after inf usion of the $20.0 \mu \mathrm{g}$ dose. In general, food-restricted rats displayed hyperlocomotion, whereas ad libitum fed rats displayed a distinctly weaker locomotor response which, in some cases, was followed by hypoactivity. The hyperlocomotion observed in the foodrestricted rats seemed to compete with lever pressing, as reflected in the $\sim 20 \%$ decrease in maximum reinforcement rate (Fig. 6, middle).

The bottom panel of Figure 6 presents the results of the locomotor test. In the initial habituation session and after saline injection, there was no difference in locomotor activity between the two groups. Thus, food restriction alone did not affect baseline locomotor activity. Locomotion was markedly increased by $20.0 \mu \mathrm{g}$ of MK-801 in both groups, with the effect being significantly greater in food-restricted than in ad libitum fed rats $\left(t_{(11)}=\right.$ 4.81; $p<0.001)$.

\section{Intraventricular D-amphetamine}

Intraventricular injections of D-amphetamine produced a significant decrease in the reward threshold $\left(F_{(3,33)}=30.51 ; p<0.001\right)$, with food-restricted animals displaying a greater decrease than free-feeding controls $\left(F_{(1,11)}=12.12 ; p=0.005\right)$ (Fig. 7 , top). Comparisons between groups at each dose level revealed a greater effect in food-restricted rats at both the 50.0 and $100.0 \mu \mathrm{g}$ dose levels $\left(t_{(11)}=3.13 ; p<0.005 ; t_{(11)}=2.94 ; p<0.01\right.$, respectively). Neither the maximum reinforcement nor response rate were affected by D-amphetamine $\left(F_{(3,33)}=0.54 ; F_{(3,33)}=\right.$ 1.14 , respectively) or feeding condition $\left(F_{(1,11)}=1.63 ; F_{(1,11)}=\right.$ 0.22 , respectively), nor was there an interaction between factors $\left(F_{(3,33)}=0.16 ; F_{(3,33)}=0.20\right.$, respectively $)$.

Finally, amphetamine $(100.0 \mu \mathrm{g})$ increased locomotor activity (Fig. 7, bottom) with a significantly greater effect in foodrestricted rats than in controls $\left(t_{(10)}=1.96 ; p<0.05\right)$.

\section{Effects of food restriction on LHSS thresholds}

Previous research indicates that some subjects display decreases in LHSS threshold as a consequence of food restriction itself (Carr and Wolinsky, 1993; Abrahamsen et al., 1997). Conceivably, this subset of food-restricted subjects would be particularly predisposed toward displaying potentiated drug effects. In the present study, several rats displayed appreciable $(>10 \%)$ decreases in LHSS threshold during the period of food restriction that preceded drug testing. However, the distribution of these subjects among drug treatment groups would not appear to account for the exception of nicotine from the potentiating effect of food restriction. The nicotine group contained at least as many (i.e., three) of these subjects as did the other groups (systemic MK-801 group contained three and the intracerebroventricular drug group contained two). Furthermore, inspection of individual results did not suggest that animals whose thresholds declined during food-restriction were more responsive to drug treatment than other food-restricted rats. This impression agrees with the previous finding of Abrahamsen et al. (1997).

\section{Histology}

Self-stimulation electrodes of the 68 subjects were widely distributed throughout the lateral hypothalamic area, spanning the
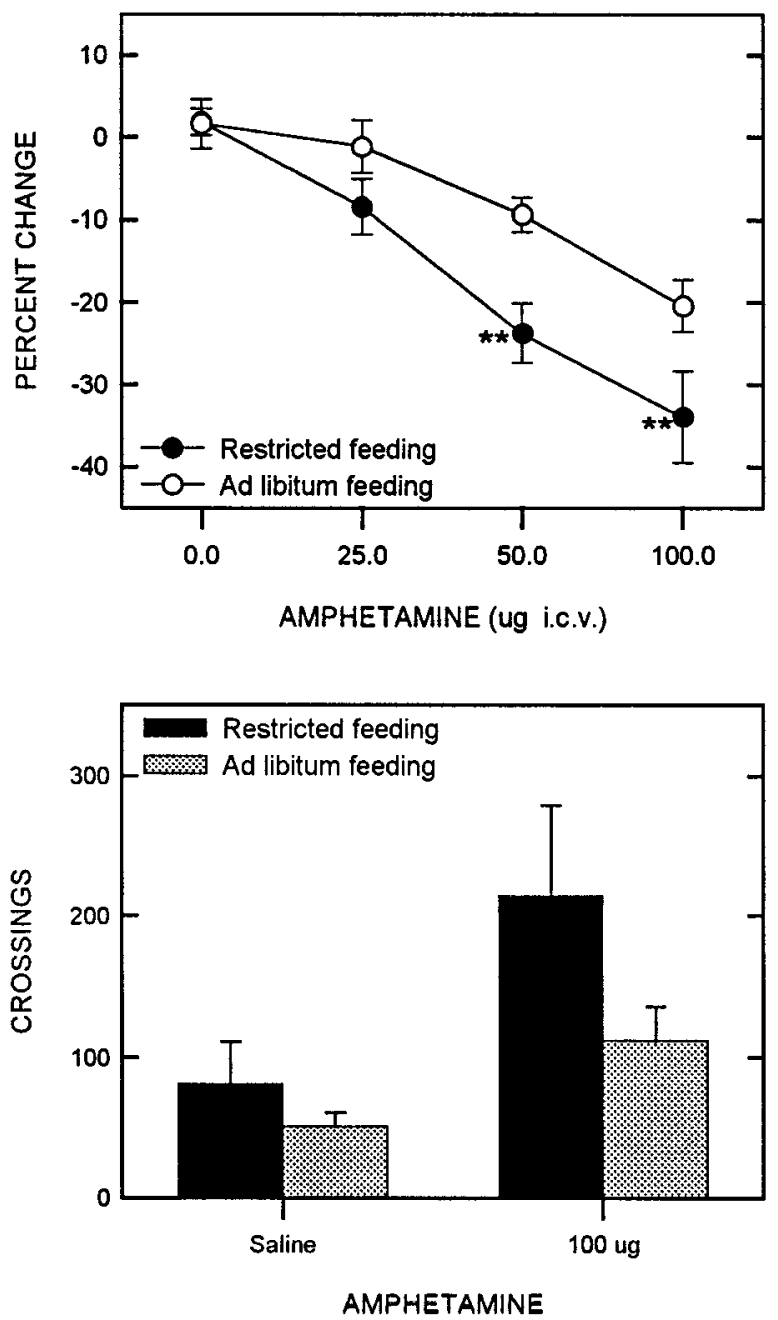

Figure 7. Mean \pm SEM percentage of change in reward threshold (top) as a function of D-amphetamine dose for food-restricted (filled circles) and ad libitum fed (open circles) rats. Reward thresholds were derived from LHSS rate-frequency curves obtained immediately before and $5 \mathrm{~min}$ after intracerebroventricular injection of D-amphetamine. Bottom displays the mean number of crossings in a shuttle box during two $30 \mathrm{~min}$ tests: (1) 5 min after intracerebroventricular injection of saline, and (2) 5 min after intracerebroventricular injection of $100.0 \mu \mathrm{g}$ of D-amphetamine.

longitudinal extent of the dorsomedial nucleus, ranging mediolaterally from the medial edge of the fornix to the medial edge of the internal capsule and dorsoventrally from the zona incerta to a position just ventral to the fornix.

Though cannulas were selected for inclusion in the study based on an immediate drinking response to intracerebroventricular angiotensin II (see Materials and Methods), histology confirmed the appropriate location of guide cannula tracks.

\section{DISCUSSION}

Results of this study indicate that the potentiation of selfadministration and locomotor responses to abused drugs by food restriction extends to the threshold-lowering effect on LHSS. This may be taken as clear evidence of increased rewarding potency. The fact that this effect was preserved when drugs were administered intracerebroventricularly indicates that food restriction increases sensitivity of the neural substrate for drug reward rather than increasing potency via changes in pharmacokinetics 
and bioavailability (Angel, 1969; Gugler et al., 1974; Woolverton et al., 1980; Ma et al., 1989). Further, the potentiated locomotor response to centrally administered drugs not only establishes the CNS basis for this effect, as suggested previously by effects of amphetamine infused into the NAC (Deroche et al., 1995), but suggests that reward and locomotion, if not homologous, may be coregulated by a mechanism that mediates behavioral adaptation to negative energy balance.

The failure of food restriction to potentiate nicotine effects on LHSS is not entirely surprising given that, unlike other drugs of abuse, food restriction does not potentiate nicotine selfadministration in animals that have already acquired the response (Singer et al., 1978; de la Garza and Johanson, 1987). However, the lack of effect is probably not indicative of nicotine exerting its rewarding effect downstream from the elements whose responsiveness is increased by food restriction, because nicotine reward is believed to be exerted at the level of ventral tegmental area (VTA) dopamine (DA) cell bodies (Blaha et al., 1996; Yeomans and Baptista, 1997), whereas the other drugs tested in this study are believed to act on the terminals of these neurons or immediately postsynaptic to them (Carlezon and Wise, 1996b; Giros et al., 1996). Indeed, the D2 antagonist pimozide reverses the threshold-lowering effect of nicotine on LHSS (Huston-Lyons et al., 1993). A possible explanation for the failure of food restriction to potentiate the rewarding effect of nicotine concerns the hypothesized involvement of corticosterone in sensitization. Although the augmented locomotor response to amphetamine, cocaine, and morphine in food-restricted rats is dependent on elevated corticosterone levels (Deroche et al., 1993; Deroche et al., 1995; Marinelli et al., 1996), many behavioral and physiological effects of nicotine are diminished by corticosterone, as is $\alpha$-bungarotoxin binding in VTA and NAC (Pauly and Collins, 1993). Should the role of corticosterone in the augmentation of locomotion extend to reward, an explanation for the exception in these results might be found therein.

The augmentation of drug-induced locomotion by food restriction is believed to result from the stressful aspect of persistent underfeeding insofar as other stressors, such as repeated restraint and foot shock, also sensitize the locomotor response to psychostimulants (Piazza and Le Moal, 1996). Further, the sensitizing effect of chronic stress is similar to that of intermittent psychostimulant administration and may result from common effects of the two treatments on the mesocorticolimbic dopamine pathway (for review, see Kalivas and Stewart, 1991). However, in contrast with chronic stress, food restriction produces behavioral adaptations aimed at preservation of energy homeostasis, including an enhancement of the hedonic response to food (Cabanac, 1971; Berridge, 1991). Thus, the potentiation of drug reward by food restriction may be a manifestation of stress-induced sensitization or, alternatively, a byproduct of the homeostatic regulation of a common neural substrate for food and drug reward. Although future research may clarify this issue, it would seem that the mechanism through which food restriction potentiates the threshold-lowering effect of drugs on LHSS differs from that which mediates sensitization by intermittent drug exposure. Intermittent drug exposure potentiates drug-induced locomotor responses but has no effect on threshold-lowering effects in the LHSS paradigm (Bauco et al., 1993; Carlezon and Wise, 1993; Wise and Munn, 1993; Bauco and Wise, 1997). In addition, to the extent that food restriction potentiates drug effects on LHSS and locomotion via the same mechanism, dissociability from sensitization by intermittent drug exposure is suggested by findings that potentiation of drug-induced locomotion by food restriction is blocked by adrenalectomy (Deroche et al., 1993, 1995), whereas sensitization by intermittent drug exposure is not (Badiani et al., 1995; Prasad et al., 1996). Finally, a reliable concomitant of psychostimulant-induced sensitization is a compensatory increase in striatal prodynorphin gene expression (for review, see Pierce and Kalivas, 1997); food restriction has no effect on striatal prodynorphin gene expression (Berman et al., 1997).

It has been hypothesized that the potentiating effect of food restriction on drug-induced locomotion may result from an increase in stimulated release of DA in NAC and/or a change in postsynaptic DA receptor binding or signal transduction (Piazza and Le Moal, 1996). This hypothesis is supported by the finding that food-restricted rats display increased NAC DA release in response to systemic cocaine (Rouge-Pont et al., 1995). However, it has also been reported that food-restricted rats display decreased NAC DA release in response to systemic amphetamine and morphine (Pothos et al., 1995). Further, food restriction has no effect on D1 or D2 receptor binding in NAC (Pothos et al., 1995). The fact that food restriction does not increase basal levels of DA in NAC suggests that the potentiation of reward is either mediated by a site downstream from NAC DA terminals or is only expressed in response to stimulation. Although the potentiation of amphetamine effects suggests that an increase in stimulated DA release could account for the present findings, the potentiation of MK-801 effects is suggestive of a site downstream from the DA neurons. Carlezon and Wise (1996b) argue that MK-801 exerts its rewarding effect by blocking NMDA receptor-mediated excitation of GABAergic medium spiny neurons in NAC that receive convergent inhibitory inputs from VTA DA neurons. Their evidence is that self-administration of MK-801 into the NAC shell is not blocked by the D2 antagonist sulpiride, whereas self-administration of the indirect DA agonist, nomifensine, is. This hypothesis is supported by the finding that systemic doses of MK-801 that have no effect on NAC DA release or cocaineinduced DA release nevertheless potentiate the reinforcing effect of self-administered cocaine (Pierce et al., 1997). Thus, if MK801 exerts its rewarding effect postsynaptic to the DA neurons in NAC, the mechanism that accounts for increased rewarding potency may be located within those postsynaptic neurons or further downstream in the reward pathway. A caveat to this line of reasoning, however, is that systemically administered MK-801 can increase the firing rate of VTA DA neurons (Zhang et al., 1992). Because hemitransection between forebrain and midbrain decreases this effect (Zhang et al., 1992), the excitatory response may result from blockade of a forebrain glutamatergic pathway that otherwise tonically inhibits VTA DA neurons, possibly via GABAergic interneurons. Thus, it is not certain that rewarding and locomotor effects of intracerebroventricular MK-801 are due solely to direct effects on NAC glutamatergic transmission.

Although the metabolic-endocrine signal that triggers the potentiation of drug reward by food restriction remains to be determined, elevated corticosterone has been implicated in augmentation of the locomotor response. Adrenalectomy and acute injection of metyrapone, a corticosteroid synthesis inhibitor, block the effect of food restriction on psychostimulant-induced locomotion (Deroche et al., 1993; Marinelli et al., 1996). Moreover, levels of circulating corticosterone potently influence selfadministration of cocaine and amphetamine (Goeders and Guerin, 1996; Piazza and Le Moal, 1996). Whether food restriction-induced elevation of corticosterone accounts for the potentiation of drug effects on LHSS has not been tested. How- 
ever, it was recently observed that the potentiated thresholdlowering effect of aminoglutethimide on LHSS in food-restricted rats is not blocked by adrenalectomy (Abrahamsen et al., 1997). Furthermore, unlike locomotion and drug self-administration, the rewarding effect of cocaine, as indexed by its lowering of the LHSS and medial prefrontal cortex self-stimulation thresholds, is unaffected by adrenalectomy (Abrahamsen and Carr, 1997; Carr and Abrahamsen, 1998).

Another candidate metabolic signal for the modulation of reward by food restriction is hypoinsulinemia. Decreases in plasma insulin, which characterize food restriction, translate into decreased CSF and brain levels (Woods et al., 1985). Notwithstanding the suggestion that food restriction mediates its effect downstream from the DA neurons (see above), it is interesting that central insulin levels regulate synthesis of the DA transporter and that hypoinsulinemia produces a decrease in DA transporter gene expression (Figlewicz et al., 1996). This same effect is produced by chronic psychostimulant (Cerruti et al., 1994) and opiate treatments (Simantov, 1993) and is proposed to be involved in the sensitizing effect of previous drug exposure (Pierce and Kalivas, 1997). Yet, with regard to the potential involvement of either decreased insulin or increased corticosterone in sensitizing the reward system to drugs of abuse, it is curious that rats rendered diabetic by alloxan or streptozotocin, who, like food-restricted rats, display low insulin and high corticosterone levels, show a diminished locomotor and NAC DA response to amphetamine and morphine (Marshall et al., 1976; Kamei et al., 1995; Murzi et al., 1996).

In conclusion, the results of the present study support the hypothesis that chronic food restriction increases sensitivity of the neural substrates for rewarding and locomotor-stimulating effects of abused drugs. In the context of evidence that MK-801 exerts its rewarding effect postsynaptic to the DA neurons in NAC, the findings that both amphetamine and MK-801 are susceptible to the effect of food restriction suggest that the elements whose responsiveness is enhanced by food restriction lie downstream from the DA neurons. Future investigations aimed at evaluating the physiological basis and anatomical locus of this effect may now exploit the fact that LHSS is an effective paradigm for measuring consequent changes in drug-rewarding potency. Whether the neuroadaptations that mediate this form of reward modulation are specifically triggered by persistent negative energy balance or are a consequence of chronic stress in general, also remains to be investigated.

\section{REFERENCES}

Abrahamsen GC, Carr KD (1997) Effect of adrenalectomy on cocaine facilitation of lateral hypothalamic self-stimulation. Brain Res 755:156-161.

Abrahamsen GC, Kandawire MJ, Carr KD (1997) Aminoglutethimide, a corticosteroid synthesis inhibitor, facilitates brain stimulation reward in food-restricted rats: an investigation of underlying mechanisms. Psychopharmacology 133:405-412.

Angel C (1969) Starvation, stress and the blood-brain barrier. Dis Nerv Syst 30:94-97.

Badiani A, Morano MI, Akil H, Robinson TE (1995) Circulating adrenal hormones are not necessary for the development of sensitization to the psychomotor activating effects of amphetamine. Brain Res 673:13-24.

Bauco P, Wise RA (1997) Synergistic effects of cocaine with lateral hypothalamic brain stimulation reward: lack of tolerance or sensitization. J Pharmacol Exp Ther 283:1160-1167.

Bauco P, Wang Y, Wise RA (1993) Lack of sensitization or tolerance to the facilitating effect of ventral tegmental area morphine on lateral hypothalamic brain stimulation reward. Brain Res 617:303-308.
Berman Y, Devi L, Spangler R, Kreek MJ, Carr KD (1997) Chronic food restriction and streptozotocin-induced diabetes differentially alter prodynorphin mRNA levels in rat brain regions. Mol Brain Res 46:25-30.

Berridge KC (1991) Modulation of taste affect by hunger, caloric satiety, and sensory-specific satiety in the rat. Appetite 16:103-120.

Blaha CD, Allen LF, Das S, Inglis WL, Latimer MP, Vincent SR, Winn P (1996) Modulation of dopamine efflux in the nucleus accumbens after cholinergic stimulation of the ventral tegmental area in intact, pedunculopontine tegmental nucleus-lesioned and laterodorsal tegmental nucleus-lesioned rats. J Neurosci 16:714-722.

Cabanac M (1971) Physiological role of pleasure. Science 173:1103-1107.

Campbell BA, Fibiger HC (1971) Potentiation of amphetamine-induced arousal by starvation. Nature 233:424-425.

Carlezon WA, Wise RA (1993) Phencyclidine-induced potentiation of brain stimulation reward: acute effects are not altered by repeated administration. Psychopharmacology 111:402-408.

Carlezon WA, Wise RA (1996a) Microinjections of phencyclidine (PCP) and related drugs into nucleus accumbens shell potentiate medial forebrain bundle brain stimulation reward. Psychopharmacology 128:413-420.

Carlezon WA, Wise RA (1996b) Rewarding actions of phencyclidine and related drugs in nucleus accumbens shell and frontal cortex. J Neurosci 16:3112-3122.

Carr KD (1996) Feeding, drug abuse, and the sensitization of reward by metabolic need. Neurochem Res 21:1455-1467.

Carr KD, Abrahamsen GC (1998) Effect of adrenalectomy on cocaine facilitation of medial prefrontal cortex self-stimulation. Brain Res 787:321-327.

Carr KD, Wolinsky TD (1993) Chronic food restriction and weight loss produce opioid facilitation of perifornical hypothalamic selfstimulation. Brain Res 607:141-148.

Carroll ME, Meisch RA (1984) Increased drug-reinforced behavior due to food deprivation. Adv Behav Pharmacol 4:47-88.

Cerruti C, Pilotte NS, Uhl G, Kuhar MJ (1994) Reduction in dopamine transporter mRNA after cessation of repeated cocaine administration. Mol Brain Res 22:132-138.

Colle LM, Wise RA (1988) Effects of nucleus accumbens amphetamine on lateral hypothalamic brain stimulation reward. Brain Res 459:361-368.

de la Garza R, Johanson CE (1987) The effects of food deprivation on the self-administration of psychoactive drugs. Drug Alcohol Depend 19:17-27.

Deroche V, Piazza PV, Casolini P, Le Moal M, Simon H (1993) Sensitization to the psychomotor effects of amphetamine and morphine induced by food restriction depends on corticosterone secretion. Brain Res 611:352-356.

Deroche V, Marinelli M, Maccari S, Le Moal M, Simon H, Piazza PV (1995) Stress-induced sensitization and glucocorticoids. I. Sensitization of dopamine-dependent locomotor effects of amphetamine and morphine depends on stress-induced corticosterone secretion. J Neurosci 15:7181-7188.

Di Chiara G, North RA (1992) Neurobiology of opiate abuse. Trends Pharmacol Sci 13:185-192.

Edmonds DE, Gallistel CR (1974) Parametric analysis of brain stimulation reward in the rat. III. Effect of performance variables on the reward summation function. J Comp Physiol Psychol 87:876-884.

Figlewicz DP, Brot MD, McCall AL, Szot P (1996) Diabetes causes differential changes in CNS noradrenergic and dopaminergic neurons in the rat: a molecular study. Brain Res 736:54-60.

Giros B, Jaber M, Jones SR, Wightman RM, Caron MG (1996) Hyperlocomotion and indifference to cocaine and amphetamine in mice lacking the dopamine transporter. Nature 379:606-612.

Goeders NE, Guerin GF (1996) Effects of surgical and pharmacological adrenalectomy on the initiation and maintenance of intravenous cocaine self-administration in rats. Brain Res 722:145-152.

Gosnell BA, Lane KE, Bell SM, Krahn DD (1995) Intravenous morphine self-administration by rats with low vs high saccharin preferences. Psychopharmacology 117:248-252.

Gugler R, Shoeman DW, Azarnoff DL (1974) Effects of in vivo elevation of free fatty acids on protein binding of drugs. Pharmacology 12:160-165.

Hoebel BG, Monaco AP, Hernandez L, Aulisi EF, Stanley BG, Lenard L (1983) Self-injection of amphetamine directly into the brain. Psychopharmacology 81:158-163. 
Huston-Lyons D, Sarkar M, Kornetsky C (1993) Nicotine and brainstimulation reward: interactions with morphine, amphetamine and pimozide. Pharmacol Biochem Behav 46:453-457.

Kalivas PW, Stewart J (1991) Dopamine transmission in the initiation and expression of drug- and stress-induced sensitization of motor activity. Brain Res Rev 16:223-244.

Kamei J, Ohsawa M, Saitoh A, Iwamoto Y, Suzuki T, Misawa M, Nagase H, Kasuya Y (1995) Modification of $\mu$-opioid agonist-induced locomotor activity and development of morphine dependence by diabetes. J Pharmacol Exp Ther 274:700-706.

Koob GF (1992) Drugs of abuse: anatomy, pharmacology and function of reward pathways. Trends Pharmacol Sci 13:177-184.

Kornetsky C, Esposito RU (1979) Euphorigenic drugs: effects on the reward pathways of the brain. Fed Proc 38:2473-2476.

Ma Q, Dannan GA, Guengerich FP, Yang CS (1989) Similarities and differences in the regulation of hepatic cytochrome P-450 enzymes by diabetes and fasting in male rats. Biochem Pharmacol 38:3179-3184.

Marinelli M, Le Moal M, Piazza PV (1996) Acute pharmacological blockade of corticosterone secretion reverses food restriction-induced sensitization of the locomotor response to cocaine. Brain Res 724:251-255.

Marshall JF, Friedman MI, Heffner TG (1976) Reduced anorectic and locomotor-stimulant action of D-amphetamine in alloxan-diabetic rats. Brain Res 111:438-442.

Miliaressis E, Rompre PP, Laviolette P, Philippe L, Coulombe D (1986) The curve-shift paradigm in self-stimulation. Physiol Behav 37:85-91.

Murzi E, Contreras Q, Teneud L, Valecillos B, Parada MA, De Parada MP, Hernandez L (1996) Diabetes decreases limbic extracellular dopamine in rats. Neurosci Lett 202:141-144.

Pauly JR, Collins AC (1993) An autoradiographic analysis of alterations in nicotinic cholinergic receptors following 1 week of corticosterone supplementation. Neuroendocrinology 57:262-271.

Phillips GD, Howes SR, Whitelaw RB, Wilkinson LS, Robbins TW, Everitt BJ (1994) Isolation rearing enhances the locomotor response to cocaine and a novel environment, but impairs the intravenous self-administration of cocaine. Psychopharmacology 115:407-418.

Piazza PV, Le Moal M (1996) Pathophysiological basis of vulnerability to drug abuse: role of an interaction between stress, glucocorticoids, and dopaminergic neurons. Annu Rev Pharmacol Toxicol 36:359-378.

Pierce RC, Kalivas PW (1997) A circuitry model of the expression of behavioral sensitization to amphetamine-like psychostimulants. Brain Res Rev 25:192-216.

Pierce RC, Meil WM, Kalivas PW (1997) The NMDA antagonist, dizocilpine, enhances cocaine reinforcement without influencing mesoaccumbens dopamine transmission. Psychopharmacology 133:188-195.

Pothos EN, Creese I, Hoebel BG (1995) Restricted eating with weight loss selectively decreases extracellular dopamine in the nucleus accumbens and alters dopamine response to amphetamine, morphine, and food intake. J Neurosci 15:6640-6650.

Prasad BM, Ulibarri C, Kalivas PW, Sorg BA (1996) Effect of adrenalectomy on the initiation and expression of cocaine-induced sensitization. Psychopharmacology 125:265-273.
Robledo P, Maldonado R, Koob GF (1993) Neurotensin injected into the nucleus accumbens blocks the psychostimulant effects of cocaine but does not attenuate cocaine self-administration in the rat. Brain Res 622:105-112.

Rouge-Pont F, Marinelli M, Le Moal M, Simon H, Piazza PV (1995) Stress-induced sensitization and glucocorticoids. II. Sensitization of the increase in extracellular dopamine induced by cocaine depends on stress-induced corticosterone secretion. J Neurosci 15:7189-7195.

Sharma HS, Cervos-Navarro J, Dey PK (1991) Increased blood-brain barrier permeability following acute short-term swimming exercise in conscious normotensive young rats. Neurosci Res 10:211-221.

Sills TL, Crawley JN (1996) Individual differences in sugar consumption predict amphetamine-induced dopamine overflow in nucleus accumbens. Eur J Pharmacol 303:177-181.

Sills TL, Vaccarino FJ (1994) Individual differences in sugar intake predict the locomotor response to acute and repeated amphetamine administration. Psychopharmacology 116:1-8.

Simantov R (1993) Chronic morphine alters dopamine transporter density in the rat brain: possible role in the mechanism of drug addiction. Neurosci Lett 163:121-124.

Singer G, Simpson F, Lang WJ (1978) Schedule induced self injections of nicotine with recovered body weight. Pharmacol Biochem Behav 9:387-389.

Stolerman IP, Bunker P, Jarvik ME (1974) Nicotine tolerance in rats: role of dose and dose interval. Psychopharmacologia (Berl) 34:317-324.

Wise RA (1982) Common neural basis for brain stimulation reward, drug reward, and food reward. In: The neural basis of feeding and reward (Hoebel BG, Novin D, eds), pp 445-454. Brunswick, ME: Haer Institute.

Wise RA (1996) Addictive drugs and brain stimulation reward. AnnU Rev Neurosci 19:319-340.

Wise RA, Bozarth MA (1987) A psychomotor stimulant theory of addiction. Physiol Rev 94:469-492.

Wise RA, Munn E (1993) Effects of repeated amphetamine injections on lateral hypothalamic brain stimulation reward and subsequent locomotion. Behav Brain Res 55:195-201.

Woods SC, Porte D, Bobbioni E, Ionescu E, Sauter JF, RohnerJeanrenaud FR, Jeanrenaud B (1985) Insulin: its relationship to the central nervous system and to the control of food intake and body weight. Am J Clin Nutr 42:1063-1071.

Woolverton WL, Martin BR, Balster RL (1980) Modification of the behavioral effects of phencyclidine by repeated drug exposure and body weight changes. Pharmacol Biochem Behav 12:761-766.

Yeomans J, Baptista M (1997) Both nicotinic and muscarinic receptors in ventral tegmental area contribute to brain-stimulation reward. Pharmacol Biochem Behav 57:915-921.

Zhang J, Chiodo LA, Freeman AS (1992) Electrophysiological effects of MK-801 on rat nigrostriatal and mesoaccumbal dopaminergic neurons. Brain Res 590:153-163. 